\title{
The Challenge for Innovation in Direct Restorative Materials
}

\section{S. Bayne ${ }^{1 *}$, P.E. Petersen ${ }^{2}$, D. Piper ${ }^{3}$, G. Schmalz ${ }^{4}$, and D. Meyer}

${ }^{1}$ School of Dentistry, University of Michigan, Ann Arbor, MI, USA; ${ }^{2}$ World Heath Organization, Global Health Programme, Geneva, Switzerland; ${ }^{3}$ Deputy Head, Chemicals Branch, Division of Technology, Industry and Economics, United Nations Environment Programme, Geneva, Switzerland; ${ }^{4}$ University of Regensburg, Germany; and ${ }^{5}$ Division of Science, American Dental Association, 211 East Chicago Avenue, Chicago, IL, USA; *corresponding author, sbayne@umich.edu

Adv Dent Res 25(1):8-17, 2013

\section{ABSTRACT}

During the past 50 years, a series of key UN conferences have established a framework to minimize human health risks from environmental exposures to key chemicals. In January 2013, more than 140 countries agreed to the text of new treaty to minimize $\mathrm{Hg}$ effects on the environment (the Minamata Convention). Dental caries is omnipresent around the globe, affecting $60 \%$ to $90 \%$ of school children and most adults, and producing discomfort that affects quality of life. Dental amalgam is frequently used to treat carious lesions and its use releases mercury into the environment. The best way to avoid the use of dental amalgam is to emphasize caries prevention. Alternatives to amalgam are suitable in some applications, but no replacement for amalgam has been found for large posterior restorations. For any restorative material, safety and environmental impacts are part of clinical risk assessment. Safety is freedom from unacceptable risks. Risk is a combination of probability of exposure and severity of harm. Best management practices are crucial to manage dental amalgam, but these impose additional that are disproportionately more for developing countries. The Minamata Convention seeks a phase-out of all mercury-based products except dental amalgam, where a phase-down is the present goal. For dentistry, the most important focus is the promotion of caries prevention and research on new materials.

$\mathbf{T}$ he challenges for dentistry associated with better management of mercury $(\mathrm{Hg})$ involve efforts to reduce or prevent dental caries, substitution of new or other materials for dental DOI: $10.1177 / 0022034513506904$

(C) International \& American Associations for Dental Research amalgam whenever possible, and environmental protection from dental materials use, including, obviously, impacts from $\mathrm{Hg}$. A new general-purpose restorative material is needed as an amalgam alternative. This transition is reviewed from the point of view of international efforts at prevention, coordination of $\mathrm{Hg}$ management with a UNEP treaty, concern for adverse reactions from any treatments, and best-management practices with economic impacts in practice for diminishing amalgam use.

\section{GLOBAL PERSPECTIVE ON DENTAL CARIES, PREVENTION, AND TREATMENT}

Dental caries affects about $60 \%$ to $90 \%$ of schoolchildren and the majority of adult people around the globe (Petersen, 2008). The disease is a major cause of pain or discomfort, and poor dental conditions considerably impair oral functioning and quality of life. Ultimately, severe loss of natural teeth affects nutrition because of the individual's inability to chew foods properly and imposes a burden on both the individual and society. Analysis of data available in the WHO Global Oral Health Data Bank (WHO, 2011) indicates that the proportion of teeth with untreated caries is high among children in most countries, while among adults, dental caries appears to result in tooth extraction. Universally, the burden of disease is high among poor and disadvantaged people compared with that in wealthy population groups (Petersen, 2005). For the vast majority of countries, the amount of untreated dental caries (dt/DT) contributes significantly to the total caries experience, as measured by the $\mathrm{dmft}$ and DMFT (decayed, missing, filled teeth; small and capital letters indicate deciduous and permanent teeth, respectively) indices. This pattern is documented for most countries within each of the WHO Regions, and selected data for those standard age groups, as recommended by WHO, can be seen in Fig. 1 .

Over the past 2 decades or so, dental caries has declined considerably in certain developed countries, while the disease now escalates rapidly in developing countries (Petersen, 2003, 2008). Marked differences exist between developed and developing countries, although not all developed countries show the same underlying factors. Oral disease prevention in developed countries has been implemented as part of public health programs. Several of these countries have established automatic fluoridation systems. Fluoride administration through water, salt

\section{Key Words}

dental caries, prevention, alternative restorative material, WHO, risk assessment, recycling, dental amalgam. 


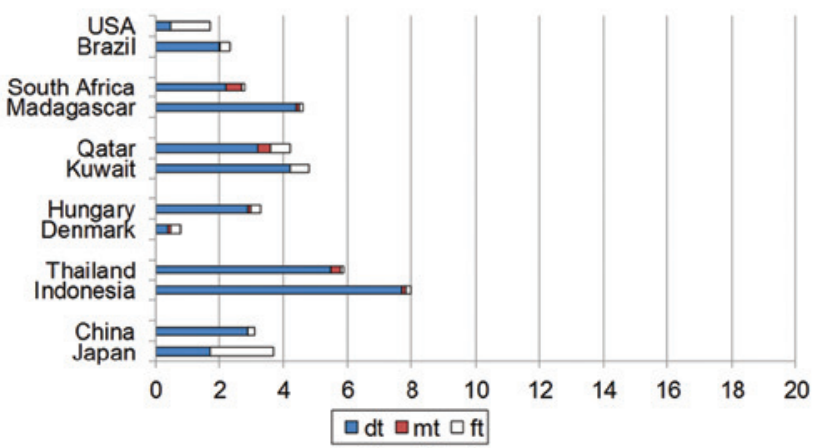

(a)

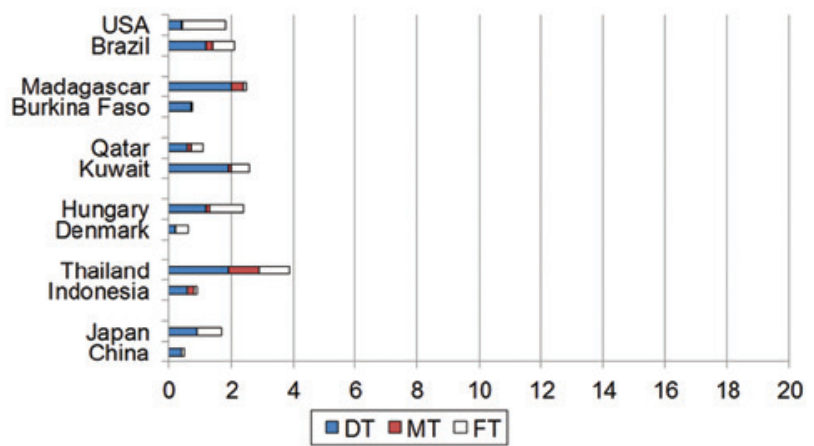

(b)

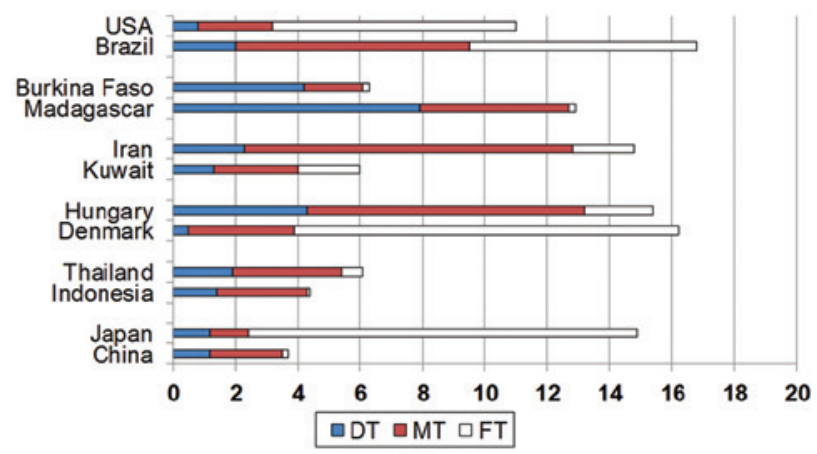

(c)

Figure 1. Mean dental caries experience in populations of selected countries as measured by the dmft or DMFT (decayed, missing, filled teeth; small and capital letters indicate deciduous and permanent teeth, respectively) indices at ages (a) 5-6, (b) 12, and (c) 35 to 44 years (WHO, 2011 ).

or milk, and fluoride-containing toothpaste is now readily available. Additional important factors are improved living conditions, adoption of healthy lifestyles, and regular use of preventive oral health services. In developing countries, however, dietary practices are changing dramatically; in particular, the consumption of sugars has increased (WHO, 2003; Moynihan and Petersen, 2004). Some of these countries are implementing preventive programs and changing their caries indices.

There is a tremendous need for "prevention of dental caries," and consideration should be given to the fact that tooth extraction equals failure. Efficiency of dental caries prevention methods has been substantiated in several countries around the world. However, despite this knowledge, not all countries have or will implement such public health programs in the near future. Many people who have suffered from dental caries need their teeth restored to normal function. Failure to do this will undoubtedly result in loss of teeth. Oral health promotion programs do not exist in many countries, and oral health services may provide only emergency care aimed at the relief of pain. Such care leads mostly to tooth extraction, which is a simpler and less expensive form of treatment. Cultural beliefs and traditions are factors that may strongly affect the acceptability of services, and in several countries there are insufficient numbers of oral health professionals to provide care to the population.

Many people around the world need to have their decayed teeth restored to normal function. Countries that provide restorative services usually prefer materials that are safe, effective, available, easy to use, and long-lasting. Dental amalgam has been used for dental restoration over the past 150 years and is considered to be safe. Meanwhile, over the past 10 years or so, the awareness and recognition of the environmental implications of mercury have increased, and dentistry as a source of environmental contamination has gained further attention.

Alternative restorative materials are obtainable in developed countries, but controversy regarding the longevity of restorations, especially in high-load-bearing areas in posterior teeth, combined with availability and cost, is a decisive factor for the utilization of alternative restorative materials in a large scale in public health programs. In countries where third-party payment schemes exist, procedures made with alternative materials may not be eligible for equal reimbursement through public or private insurance systems. Resin-based and glass-ionomer materials, or combinations thereof, are found in some countries but are not used widely, and some practitioners consider them as temporary procedures. The rationale is that their quality is not as good as that of dental amalgam. Therefore, many challenges are faced by developing countries in providing adequate health care services to populations, and the choice of materials for dental restoration is limited. The challenge to the research community and industry, therefore, is to develop safe materials that are of good quality, easy to use, long-lasting, and with little or no severe impact on the environment, all at a reasonable cost. It is critical that, in the development plan, public health be taken into consideration. As the specialized agency responsible for health, 
WHO should be able to advise member countries on the best courses of action to provide satisfactory health care services to the population, with the ultimate goal of maintaining and improving oral health. Educational institutions have the responsibility of educating future oral health care providers and training health professionals on alternative restorative materials, and of encouraging third-party payment providers to include reimbursement for procedures that include alternative dental materials.

Strengthening disease prevention and health promotion is the pivotal approach for reducing the need for restorative care. Choices of dental restorative materials depend on several factors, including lesion size, lesion location, tooth type, resistance to wear, and durability. The meeting recognized needs for strengthening research into long-term performance, possible adverse effects, and viability of alternative materials. Moreover, the appropriate infrastructure for the delivery of optimal dental care and effective distribution systems relevant to the use of dental materials remain important challenges to developing countries. Notably, some countries require systems for waste management to prevent the release of mercury into the environment. The WHO meeting suggested essential research strategies for new, quality materials for dental restorations to be developed and to become available for public health care. To this end, the International Association for Dental Research is a vital partner to WHO in serving Member States with information on evidence-based dental care around the globe.

The WHO Global Oral Health Programme has disseminated evidence-based information about restorative dental care to its member states, and recommendations have been made for the utilization of best management practices to handle amalgam waste (WHO 2010). However, essential equipment such as amalgam separators is seldom available in developing countries, and recycling programs or facilities are either limited or nonexistent in these countries, making best management practices difficult to implement. These challenges continue to be investigated from both the recapture and recycling points of view. Currently, there is a project in Brazil for mercury recovery that decreases the processing time and produces mercury at a high level of purity (Iano et al., 2008).

In response to initiatives on mercury reduction and the request from Member States for guidance on dental care, the World Health Organization (WHO), in cooperation with the United Nations Environment Programme (UNEP), organized a technical consultation in Geneva in 2009 (WHO, 2010) to discuss the implications of the use of dental restorative materials. The overall aim of the meeting was to assess the scientific evidence available on the use of dental restorative materials, particularly the potential use of restorative alternatives to dental amalgam. Dental care and cost implications were discussed with special reference to the situation in developing countries.

\section{REVIEW OF THE DEVELOPMENT OF GLOBAL POLICY ON MERCURY}

Over the past 40 years, and in response to the UN Conference on the Human Environment held in Stockholm in 1972, the Earth Summit held in Rio in 1992, and the World Summit on Sustainable
Development held in Johannesburg in 2002, the international community has developed a framework of legislation to minimize the risks to human health and the environment from exposure to chemicals of particular concern.

Some of the international treaties now in place seek to eliminate the production, use, trade, and release of particular chemicals and chemical groups, while others seek to regulate particular stages in the life-cycle of wider groups of substances (Fig. 2). The Montreal Protocol on Substances that Deplete the Ozone Layer (Ozone Secretariat, 2011) and the Stockholm Convention on Persistent Organic Pollutants (Stockholm Convention, 2008) are examples of the former. The Rotterdam Convention on the Prior Informed Consent Procedure for Certain Hazardous Chemicals and Pesticides in International Trade (Rotterdam Convention, 2008) and the Basel Convention (2011) on the Control of Transboundary Movements of Hazardous Wastes and their Disposal represent the latter.

Each of these agreements, negotiated by governments, is now in force, and most governments have become parties and accepted legal obligations at the national level to implement the control measures set out in the treaties. Governments have also accepted legal obligations under the International Health Regulations (WHO, 2008) and may be parties to conventions of the International Labour Organization governing occupational health and work place safety (International Labour Organization, 2013). In 2006, governments adopted the Strategic Approach to International Chemicals Management (SAICM) to provide an overarching policy framework for the sound management of chemicals.

Most recently, in January 2013, more than 140 governments agreed to the text of a new treaty that seeks to phase out or minimize human use of mercury and avoid its release into the environment from human activity (Fig. 3). The Minamata Convention on Mercury (United Nations Environment Programme, 2013a) is to be approved at a diplomatic conference in October 2013, when high-level representatives will meet in Japan to sign the accord to indicate the intention of their governments to ratify the treaty. When 50 countries have ratified, it is expected to be adopted in October 2013, and to enter into force in about 3 years' time.

Agreement on the treaty follows many years of assessment of the impacts of human use of mercury. While the adverse effects of mercury on human health have long been known, scientific evidence of its impact on the environment has been building steadily. There is now good evidence of the behavior of mercury in environmental media - the air, water, and soils (UNEP and AMAP, 2013). Well-constrained models highlight its ability to be transported long distances from its release, to transfer repeatedly between environmental media, to be transformed from less toxic metallic forms into highly toxic methyl-mercury, and to bio-accumulate, particularly through the marine food webs, ultimately in humans through food.

The recently published UNEP Global Mercury Assessment (UNEP, 2013b) (Fig. 4) estimates that, in 2010, global emissions of mercury to air from anthropogenic sources amounted to 1,960 tons. The Assessment also estimates anthropogenic releases of mercury to water of at least a further 1,000 tons. The Assessment notes that while mercury is also emitted from natural 
sources such as volcanoes, anthropogenic emissions have exceeded natural emissions since the start of the industrial age, about 200 years ago, so that the bulk of mercury circulating in the environment is likely to be from human activity.

The Assessment also provides estimates of emissions from key sectors. Approximately half of estimated emissions result from the presence of mercury as a trace contaminant in coal, non-ferrous metal ores, and limestone. Mercury is emitted when these rocks and minerals are processed - burning coal to generate electrical power, smelting ore to produce metals, and calcining limestone to make cement. The remainder of estimated emissions results from the intentional use of mercury in a variety of processes and products, most notably in artisanal and small-scale gold mining, where mercury is added to the ore or concentrate to 'collect' any gold into an amalgam that is then heated to drive off the mercury, leaving the gold. This is particularly difficult to manage in developing countries where this type of industry may be the principal source of employment. In industry, mercury finds use as a catalyst or electrode and may be emitted during operations or released from badly managed stocks.

An estimated 1,000 to 1,500 metric tonnes per year of mercury are used in the manufacture of a range of products, including particular forms of batteries, fluorescent lighting, switches and relays, medical devices, and dental amalgam (UNEP, 2013c). In most of these applications, mercury use is declining as market share is increasingly taken up by mercury-free alternatives that meet the same standards of performance and are readily available at equivalent prices. One final caution is that these are estimates only. It is difficult to obtain reliable data because $\mathrm{Hg}$ may be commercialized on the black market in many countries and hence is not available for measurement.

The text of the new Minamata Convention on Mercury reflects the availability of mercury-free alternatives in most applications by setting out, in Annex A, 2020 as the date by which mercurycontaining products must be phased out. However, governments recognized that the availability and cost of alternatives can vary widely, and that some states may have difficulties in meeting the phase-out date. In these circumstances, allowance is made for time-limited specific exemptions.

Dental amalgam accounts for about a quarter of total demand for mercury in products (UNEP, 2013b). Recent analyses commissioned by the European Commission and others have highlighted that current pricing structures for dental amalgam do not factor in the negative externalities associated with its use - in particular; the costs arising from emissions and releases of mercury arising from inadequate management practices associated with dentistry.

Since 2009, UNEP and WHO have jointly promoted a phasedown approach to dental amalgam. The approach recognizes that while dental caries is avoidable and there should be emphasis on prevention, there is likely to be a long-term continuing need for dental restorative care, and that, while restorative materials alternative to amalgam are available and desirable, experiences with respect to dental care differ widely around the world, making it likely that amalgam will continue to be needed in many countries for some time to come. The report 'Future Use of Materials for Dental Restoration' (WHO, 2010), published by WHO in 2010 following an expert meeting convened by WHO and UNEP in 2009, sets out the phase-down approach and identifies roles and responsibilities of stakeholders in promoting it, including a strengthened research agenda to identify suitable alternative materials for dental restoration that avoid the use mercury and other hazardous materials.

During the negotiations, the challenges in eliminating the use of dental amalgam were identified, and negotiators decided to list it separately in Annex A of the treaty and to set out measures to be taken by parties to the convention to phase down its use (UNEP, 2013a). No date for its prohibition from manufacture and trade was set.

Measures to be taken by a party in phasing down the use of dental amalgam need to take into account the domestic circumstances of parties to the convention as well as relevant international guidance. Parties are expected to take up measures that closely follow the UNEP-WHO approach and include all of the following:

- Setting national objectives toward dental caries prevention and health promotion, minimizing amalgam use and limiting use to its encapsulated form.

- Promoting the use of cost-effective and clinically effective mercury-free alternatives.

- Encouraging education and training of dental professionals and students on the use of mercury-free dental restoration alternatives and on best management practices. 


\section{Intergovernmental Negotiating Committee}

INC2

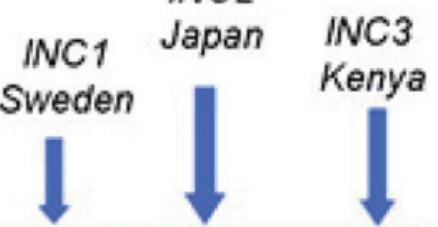

INC4

Uruguay
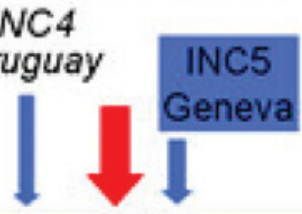

2011

2012

2013

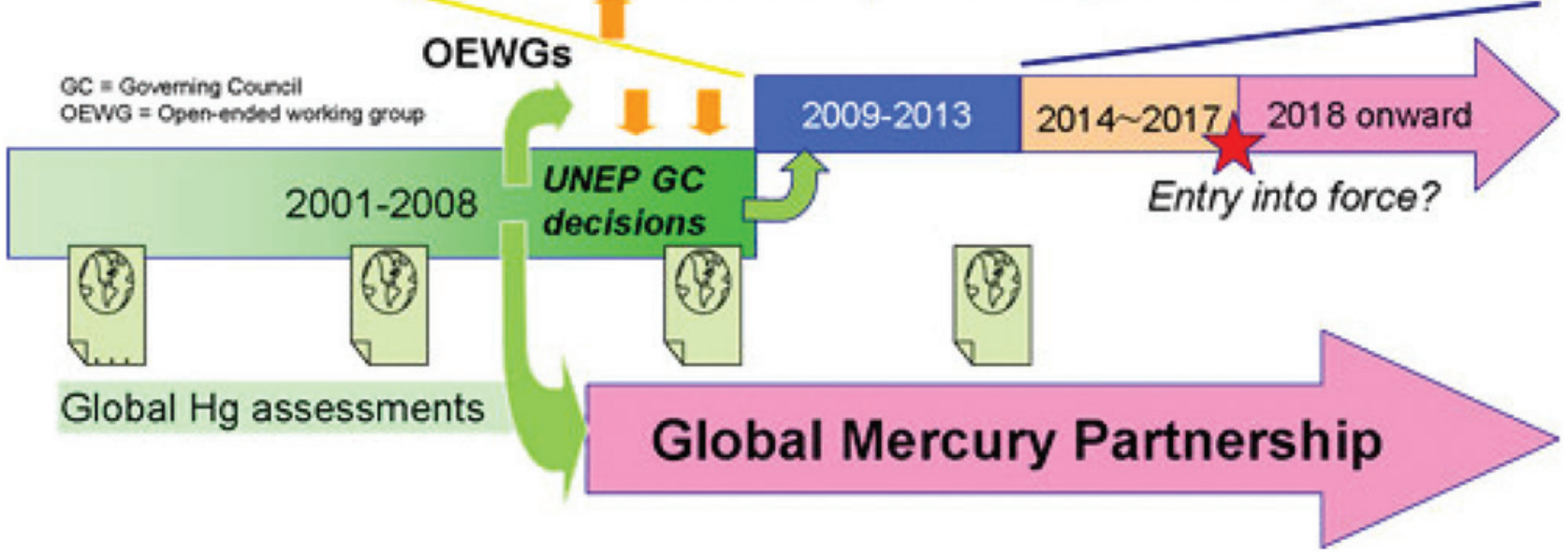

Figure 3. UNEP global mercury program (a twin-track approach). Adapted from UNEP, 2013b.

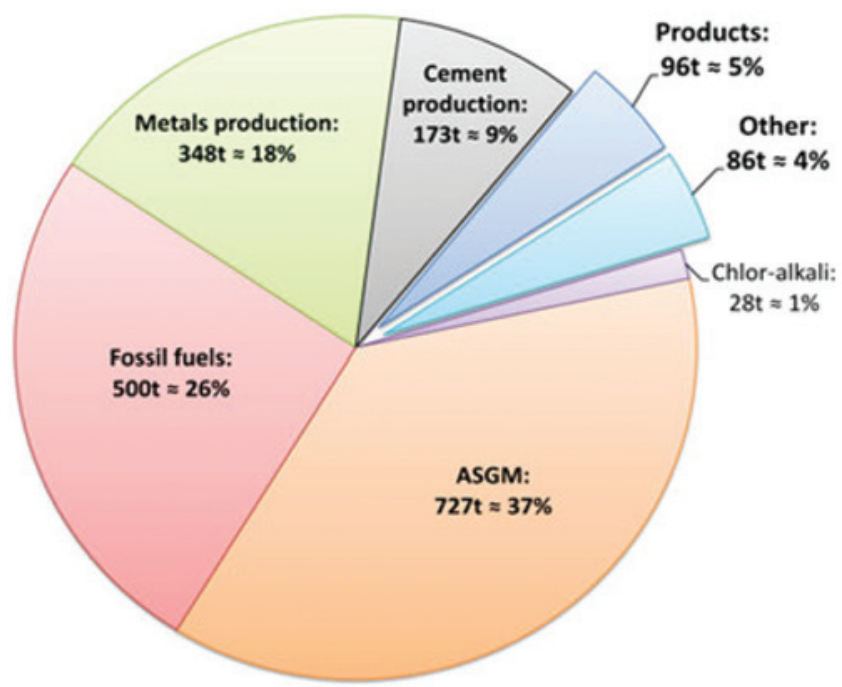

Figure 4. Anthropogenic $\mathrm{Hg}$ emissions to air (2010 estimates, tons and percentages).

- Promoting research and development of quality mercury-free materials for dental restoration.

- Discouraging insurance policies and programs that favor dental amalgam use over mercury-free dental restoration and encouraging those that favor the use of effective alternatives.

- Promoting the use of best environmental practices in dental facilities to reduce releases of mercury and mercury compounds to water and land.
Thus, while the use of amalgam in dental restorations can continue, the dental profession and its supporting industries, working within parties to the Minamata Convention on Mercury, will need to consider their roles and responsibilities in taking up the phase-down measures set out in Annex A. This provides opportunities for innovation and the incorporation of best practices throughout dental care and at each stage in the 'life-cycle' of mercury use in dental amalgam.

\section{HUMAN SAFETY OF CURRENT DENTAL RESTORATIVE MATERIALS}

Human safety evaluation must consider the release/exposure of substances from a dental material (a) into the oral cavity of the patient, (b) to dental personnel, and (c) into the environment. Furthermore, its uptake/transport, the biologic reactions comprising systemic and local reactions, allergies, and CMR (cancerogenic, mutagenic, reprotoxic reactions), and, finally, excretion must be considered (see Table). In this work, only dental materials with widespread use are considered (i.e., materials for direct restorations, such as amalgam, resin-based composites, glass-ionomer cements, and their combinations). Understanding the risks requires defining the concentrations and times involved in exposures.

For amalgam, a great many national and international expert groups, installed by national and supranational governmental institutions in recent decades, have dealt with its biocompatibility, one of the latter being the EU (SCENIHR, 2008). It is generally 
Table. Human Safety of Dental Materials: Generalized Overview Based on Current Literature*

\begin{tabular}{|c|c|c|c|c|}
\hline Events & Reactions & Amalgam & Resin-based Material & Glass-ionomer Cements \\
\hline Release/Exposure & & $\begin{array}{l}+ \\
\text { (Hg and other ions) }\end{array}$ & $\begin{array}{l}+ \\
\text { (large variety of organic } \\
\text { chemicals, e.g., acrylic } \\
\text { monomers) }\end{array}$ & $\begin{array}{l}+ \\
\left(\mathrm{F}^{-}, \mathrm{Al}^{3+}, \text { and other ions }\right)\end{array}$ \\
\hline Uptake & & + & + & + \\
\hline \multirow[t]{4}{*}{ Adverse biologic reaction } & Systemic & $\overline{\text { (but claimed mainly for } \mathrm{Hg} \text { ) }}$ & $\overline{-}$ (role of BPA unclear) & (exception is neurosurgery) \\
\hline & Local & $\begin{array}{l}+ \\
\text { (but seldom) }\end{array}$ & $\begin{array}{l}+ \\
\text { (but seldom) }\end{array}$ & $\begin{array}{l}\text { (exception is direct pulpal } \\
\text { contact) }\end{array}$ \\
\hline & Allergic & $\begin{array}{l}+ \\
\text { (but seldom) }\end{array}$ & $\begin{array}{l}+ \\
\text { (but seldom in patients; } \\
1-2 \% \text { in dental personnel) }\end{array}$ & - \\
\hline & $\begin{array}{l}\text { Carcinogenic/Mutagenic/ } \\
\text { Reprotoxic }\end{array}$ & - & (but mutagenic in vitro) & - \\
\hline Excretion & & + & + & + \\
\hline
\end{tabular}

*See for example SCENIHR, 2008, and Schmalz and Arenholt-Bindslev, 2009.

Note: "+" = Literature indications that reactions occur; " $-"=$ No literature indications that reactions occur.

accepted that mercury in different oxidation states is released from amalgam fillings. Uptake for metallic mercury $\left(\mathrm{Hg}^{0}\right)$ occurs mainly through the lungs, with only minor parts as $\mathrm{Hg}^{2+}$ through the intestines. Ingested mercury in amalgam particles is virtually unabsorbed. Exposure is considered to be by far below the relevant limits set by WHO or other competent authorities (SCENIHR, 2008; Schmalz and Arenholt-Bindslev, 2009). Systemic biologic reactions (intoxications) are claimed, but at present the competent national and international authorities - after thorough evaluation of existing evidence - have not found these claims to be a reason to attest to dental amalgam as an unacceptable risk (SCENIHR, 2008; Schmalz and Arenholt-Bindslev, 2009). Allergies to mercury (and to amalgam), as well as local mucosal reactions, have been reported but the number of cases was rated low. Mercury is excreted via feces or urine (SCENIHR, 2008; Schmalz and Arenholt-Bindslev, 2009).

For resin-based composites, many different substances have been identified to be released to the liquid interface (saliva, dentin/pulp) (Schmalz and Arenholt-Bindslev, 2009), to ambient air in the dental setting (Marquardt et al., 2009), and as smallscale (nano) particles during filling removal (Van Landuyt et al., 2012). Mainly, monomers like HEMA, TEGDMA, or UDMA are released, but also Bis-GMA and Bis-DMA. Limited information is available on the uptake of these chemicals. Animal experiments showed uptake of TEGDMA and HEMA and their metabolism in the body. In this context, epoxy-intermediate 2, 3-epoxymethacrylic acid is formed, which is considered to be mutagenic (Schweikl et al., 2006; Durner et al., 2010). Monomers like TEGDMA or HEMA also tested mutagenic in different in vitro test systems, with DNA oxidation and consecutive single- and double-strand breaks (Schweikl et al., 2006; Eckhardt et al., 2009). The clinical consequences remain unclear.

Recently, the presence of bisphenol A (BPA) as part of the basic resin monomer Bis-GMA or (the more seldom-used) BisDMA has raised concerns about the release of BPA, which has estrogen-like effects. Available evidence shows that BPA is, under clinical conditions, not released from pure Bis-GMA. However, Bis-DMA is converted to BPA, e.g., by salivary esterases (Schmalz et al., 1999). Furthermore, BPA may be detected as residues/impurities in Bis-GMA because it may be used during the fabrication of Bis-GMA. After placement of Bis-DMAcontaining fissure sealants, BPA could be detected immediately or shortly after placement in saliva and urine, and salivary samples were estrogenic in vitro. Virtually no effect was seen a day after placement (Schmalz et al., 1999; Joskow et al., 2006; Kingman et al., 2012). Calculations of exposure levels showed that even after exposure to Bis-DMA-containing materials (fissure sealants), the amounts of BPA were below limit/reference values of classic toxicology. However, these levels are currently under discussion. Particulate aerosols are produced by the grinding and removal of resin-based composite fillings (Gioka et al., 2009; Kingman et al., 2012), and they may act like estrogen (Gioka et al., 2009). The clinical relevance and the possible environmental impact are unknown. Clearly known, however, are allergic reactions: Mainly type IV (cell-mediated) but also type I (immediate reaction, anaphylactic) reactions have been described, and dental personnel constitute a risk group (Schmalz and Arenholt-Bindslev, 2009).

Glass-ionomer cements release fluorides and aluminum ions. No systemic reactions and very few, if any, allergic reactions have been described when these are used as dental filling materials. Biological properties of various combinations of glassionomer cements and resin-based composites are determined mainly by their resin components (Schmalz and ArenholtBindslev, 2009).

A gross overview of data from the literature has been reported for the different endpoints and for the different material groups (see e.g., SCENIHR, 2008; Schmalz and ArenholtBindslev, 2009). The Table shows that differences in the biocompatibility of the 3 material groups can be seen, but it is not 
possible to generally rank them from the most to the least toxic material. Fewer allergic reactions occur with (pure) glass-ionomer cements, but their mechanical properties are insufficient for more than one surface cavities (Frencken et al., 2012).

"Clinical risk evaluation" of dental materials is based on the concept that 'safety' is freedom from unacceptable risks and 'risk' is the combination of probability (frequency) and severity of harm (in general) (ISO 14971, 2010). Epidemiological data on the frequency of adverse effects caused by dental materials are sparse, but estimates are low $(<0.1 \%)$ (Hensten-Pettersen, 1992). For comparison, cosmetics have an adverse effect rate of $12 \%$ (Orton and Wilkinson, 2004). In terms of severity, mainly allergies or local effects occur (SCENIHR, 2008; Schmalz and ArenholtBindslev, 2009). The EU report states: "All the materials are considered safe to use and they are all associated with very low rates of local adverse effects (... allergic reactions and an association with clinical features characteristic of lichen planus ...) with no evidence of systemic disease" (SCENIHR, 2008).

The longevity of a restoration is a relevant parameter as a benefit of dental restorative materials. In this respect, amalgam is still superior in large cavities and in difficult clinical situations. Resin-based composites are not replacements for amalgam in these situations. Glass-ionomer cements are useful only for one surface cavities (Class I). The risk-benefit analysis shows that dental materials on the market are generally acceptable but with different indications.

\section{ENVIRONMENTAL SAFETY OF CURRENT RESTORATIVE MATERIALS}

There are ever-increasing concerns for protecting the environment from effects of manufacture, use, and disposal of materials. Dentistry is no different. A strong emphasis in developed countries during the past decade has been the collection and recycling of amalgam waste materials. The American Dental Association (ADA) has done considerable investigation and planning over the past 2 decades, not only for dental amalgam management but also for similar issues for other restorative materials. Technical issues regarding restorative materials affect much more than just simply those associated with restoration placement and service (see Fig. 5). Waste management includes concern for residual materials from use, disposal of packaging, chairside traps, vacuum pump filters, separators, plumbing, sewer systems, crematoria, and cemeteries, to mention just a few examples (Naleway et al., 1994; Calais et al., 1994; Letzel et al., 1997; Adegbembo et al., 2002; Fan et al., 2002; McManus and Fan, 2003; VanDeven and McGinnis, 2005; ANSI/ADA, 2006; Batchu et al., 2006; US EPA, 2010, 2011, 2012).

ADA's mission statement clearly emphasizes its roles as a trusted source for oral health information and for improving public health outcomes. During the past 10 years, the ADA has promoted the use of "best management practices" (BMPs) for all dental materials (ADA, 2003, 2007). Currently, about 50\% of all the $\mathrm{Hg}$ and derivatives entering the waste stream in the United States are from dentistry (US EPA, 2011). Efforts to recapture $\mathrm{Hg}$ and derivatives within the dental office have included a range of chairside filters and separators on waste water lines (Fan et al., 2002; Chou and Anglen, 2012), which reclaim greater than $99 \%$ of those materials. The first product standard for separators was introduced in 1999 (Technical Committee ISO/TC 106, 1999). The latest standard is ISO 11143 (2008). Most products are very efficient and include approaches based on sedimentation, centrifugation, filtration, and absorption. ADA's Professional Product Review (2012) reported evaluations of all current recapture systems and compared the space, electricity, recycling paths, and lifecycle costs. There are significant costs for putting these systems in place due to existing limitations or challenges within dental offices, such as space, utility requirements, building constraints, local regulations, ease of maintenance and replacement, effects on existing suction systems, and available recycling options. The dental amalgam sellers and distributors have now become partners in this process, volunteering or contracting to manage much of the recycling of amalgam waste.

Dentistry contributed only about 0.4 ton of $\mathrm{Hg}$ or derivatives to the environment in 2004 (VanDeven and McGinnis, 2005). Adding a $\mathrm{Hg}$ separator to every dental office is estimated to reduce that environmental load by 0.1 ton (US EPA, 2010). Therefore, this approach alone is not the final solution for $\mathrm{Hg}$ management.

Exposure levels for patients are incredibly low, and $\mathrm{Hg}$ is actively excreted with the $\mathrm{Hg}$ from other normal air, water, and food exposures. Dentists who work with amalgam day-by-day have exposure levels actually lower than those of their patients.

Waste management is still challenging for developing countries and imposes an added cost for health care. Of course, prevention makes economic sense as well, and this should be stressed throughout any planning. Foremost, our goal is the promotion of health and prevention of disease, not simply the defense of dental amalgam.

Other materials have been proposed as alternatives for various applications, such as, for example, glass ionomers. Atraumatic restorative technique (ART) materials utilize glass ionomers for short-term applications to control caries and allow for patients to visit regular dental offices or care facilities. However, this material is not for use as a true amalgam substitute. Drawbacks associated with the reduced use of dental amalgam include considerations of longevity, financial costs, and technical challenges for alternative materials. In most cases, these affect developing regions more than first-world areas.

Environmental protection is the key part of this discussion. Intertwined into the current discussion for years has been the defense of dental amalgam against anti-amalgamists and their misinformation campaigns. This "emotional toxicology" has been rampant for the past 30 years in the United States. Decreasing use of dental amalgam in most developed regions has been driven mostly by preferences for adhesive dentistry and aesthetic restorations. Thus far, those options do not provide the amalgam alternative that would also offer improved performance and longevity. That is why the current discussion of potential options is so important.

\section{DISCUSSION}

Caries continues to be a huge public health problem affecting schoolchildren and many adults in all regions. Its ravages create 


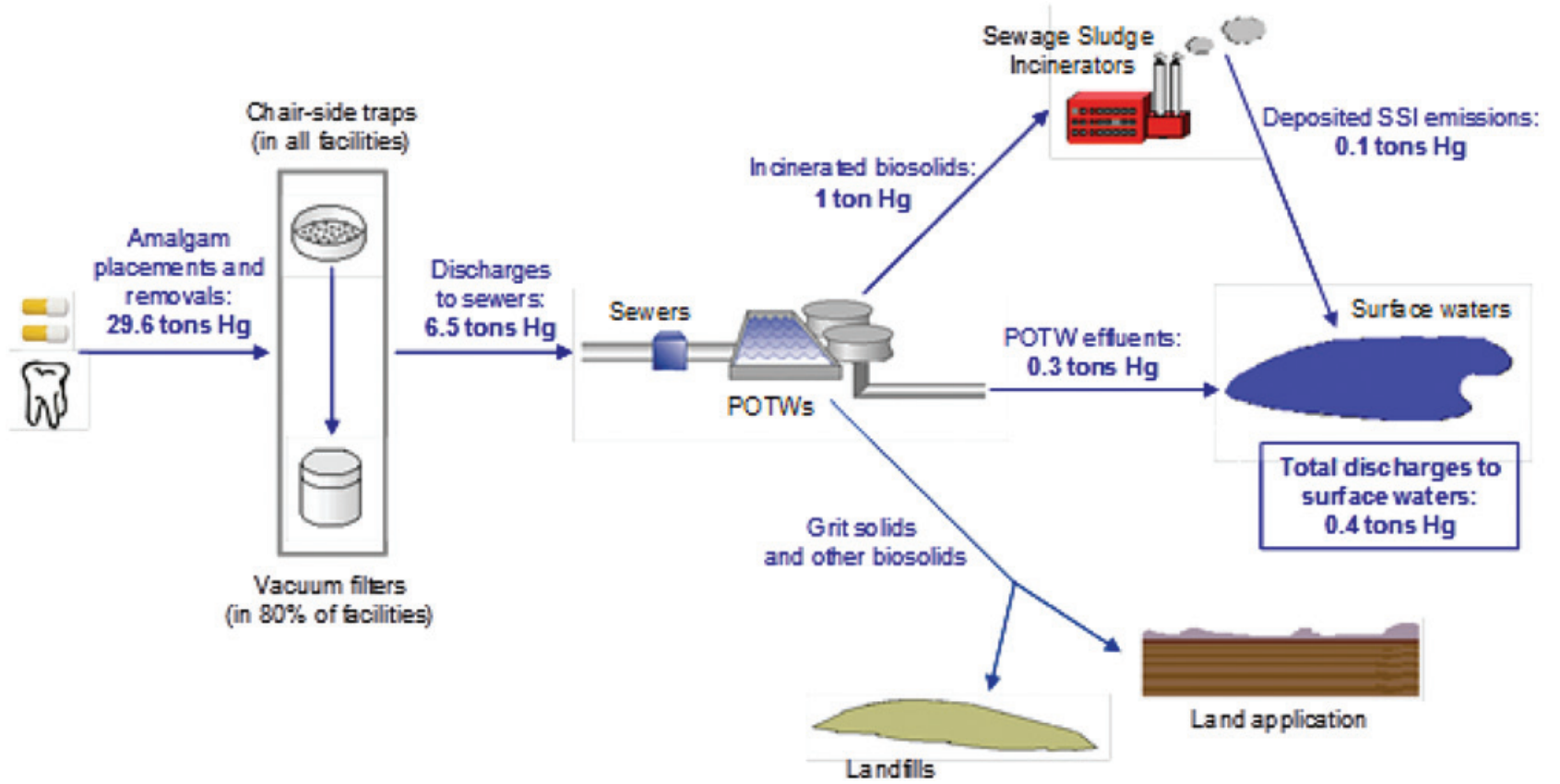

Figure 5. Estimates of dental wastewater $\mathrm{Hg}$ released into the environment.

a major public health cost. We must focus on prevention. Dental amalgam has been a major restorative tool for management of the disease in the short term. No restorative materials have the longer term performance that we seek. UNEP INC in recent times has tried to deal globally with the fact that $\mathrm{Hg}$ and its derivatives are the greatest environmental threat on the planet. Via a series of conferences, a new treaty is now proposed for adoption and signing (2013, Minamata Convention) that will document the commitments of regions to phase down amalgam use and work to contain all $\mathrm{Hg}$ impact from all industries, including dentistry.

The correct term for the process being discussed as part of the UNEP INC treaty is 'phase-down'. While some regions will phase out amalgam entirely, the goal is to decrease the need and use of dental amalgam as much as possible, but that will depend on the individual treaty signers. There already has been decreasing use of amalgam for many years in dental practices in firstworld regions due to advances in adhesive dentistry, but everyone is still waiting for a true amalgam substitute to be developed.

One of the more contentious discussions is about the relative impact of different users of $\mathrm{Hg}$ and their environmental impacts. About $20 \%$ of all use is for gold extraction associated with artisanal gold mining. In that context, the effects of dental uses seem small. However, all users must focus on reductions in $\mathrm{Hg}$ impact. The threat and challenge are the most important for our environment. At the same time, there are always political considerations. In the case of compact fluorescent lamps, for example, some temporary allowance has been granted for the trade-off in lower energy consumption associated with that application.

Safety of dental restorative materials includes concerns beyond those for dental amalgam. There is still much that is either unknown or undocumented. However, despite worries about the biological activities of components of restorative materials, they have been very successful and trouble-free when managed properly. It is important to emphasize that "safety" is freedom from unacceptable risk and not the absence of risk.

Risks go beyond those for the patient and the office personnel. Risks involve the entire path, from manufacturer, packing, distribution, delivery and storage, use, residual materials disposal, recapture of spent materials, and recycling. All of these have an impact on the global environment. Reduction in global risk demands emphasis on prevention, expanded efforts on bestmanagement practices, and development of alternative restorative approaches to provide longer-term service.

\section{SUMMARY}

Dental amalgam should be phased-down throughout the world. Alternative restorative materials with improved properties are needed for the future. A coordinated world-wide approach to research and funding for those materials is needed. Foremost, restorative dentistry must strongly promote the prevention of dental caries to reduce the need for restorative materials and emphasize the best management practices for all materials in use.

\section{ACKNOWLEDGMENTS}

Stephen C. Bayne is Chair of Cariology, Restorative Sciences, and Endodontics at the University of Michigan School of Dentistry. Poul Erik Petersen is the Responsible Officer of the World Health Organization Oral Health Programme. David Piper is the Deputy Head of the Chemicals Branch of the 
Division of Technology, Industry and Economics of the United Nations Environment Programme. Gottfried Schmalz is Chair of Conservative Dentistry and Periodontics at the University of Regensburg. Dan Meyer is Senior Vice-President, Science/ Professional Affairs, of the American Dental Association. The authors received no financial support and declare no potential conflicts of interest with respect to the authorship and/or publication of this article.

\section{REFERENCES}

Adegbembo AO, Watson PA, Lugowski SJ (2002). The weight of wastes generated by removal of dental amalgam restorations and the concentration of mercury in dental wastewater. $J$ Can Dent Assoc 68:553-558.

American Dental Association (2003). Best management practices for amalgam waste. URL accessed on 9/4/2013 at: http://www.ada.org/1540 .aspx.

American Dental Association (2007). Best management practices. URL accessed on 9/4/2013 at: http://www.ada.org/sections/publicResources/ pdfs/topics_amalgamwaste.pdf.

ANSI/ADA (2006). American National Standards Institute/American Dental Association Specification No. 109-2006. Procedures for storing dental amalgam waste and requirements for amalgam waste storage/shipment containers. URL accessed on 9/4/2013 at: http://webstore.ansi.org/ RecordDetail.aspx?sku=ANSI\%2fADA $+109-2006+($ R2012 $)$.

Basel Convention (2011). URL accessed on 9/4/2013 at: http://www.basel. int/TheConvention/Overview/TextoftheConvention/tabid/1275/ Default.aspx.

Batchu H, Chou H-N, Rakowski D, Fan PL (2006). The effect of disinfectants and line cleaners on the release of mercury from amalgam. $J \mathrm{Am}$ Dent Assoc 137:1419-1425.

Calais MD, Ovsey VG, Mihailova C, Naleway C, Batchu H, Fan PL, et al. (1994). Physical-chemical properties of dental wastewater. In: Proceedings of WEFTEC'94, Water Environment Federation, 67th Annual Conference and Exposition, 15-19 October 1994, Chicago, IL. Alexandria Naval Institute for Dental and Biomedical Research, VA. Water Environ Feder 76:317-327.

Chou HN, Anglen J (2012). An evaluation of amalgam separators. $J$ Am Dent Assoc 143:920-921.

Durner J, Walther UI, Zaspel J, Hickel R, Reichl FX (2010). Metabolism of TEGDMA and HEMA in human cells. Biomaterials 31:818-823.

Eckhardt A, Schmalz G, Hiller KA (2009). DNA oxidation by a dimethacrylate and an epoxy monomer. Arch Pharmacol 379:74.

Fan PL, Batchu H, Chou HN, Gasparac W, Sandrik J, Meyer DM (2002). Laboratory evaluation of amalgam separators. J Am Dent Assoc 133:577-584.

Frencken JE, Leal SC, Navarro MF (2012). Twenty-five-year atraumatic restorative treatment (ART) approach: a comprehensive overview. Clin Oral Investig 16:1337-1346.

Gioka C, Eliades T, Zinelis S, Pratsinis H, Athanasiou AE, Eliades G, et al. (2009). Characterization and in vitro estrogenicity of orthodontic adhesive particulates produced by simulated debonding. Dent Mater 25:376-382.

Hensten-Pettersen A (1992). Casting alloys: side-effects. Adv Dent Res 6:38-43.

Iano FG, Santos Sobrinho Od, Silva TL, Pereira MA, Figueiredo PJ, Alberguini LB, et al. (2008). Optimizing the procedure for mercury recovery from dental amalgam. Braz Oral Res 22:119-124.

International Labour Organization (2013). URL accessed on 9/4/2013 at: http://www.ilo.org/global/standards/subjects-covered-by-internationallabour-standards/occupational-safety-and-health/lang--en/index.htm.

International Organization for Standardization (2008). ISO 11143:2008. Dental equipment - amalgam separators. Geneva, Switzerland. URL accessed on 9/4/2013 at: http://www.iso.org/iso/iso_catalogue/catalogue_tc/catalogue_detail.htm?csnumber $=42288$.

International Organization for Standardization (2010). ISO 14971:2010. Medical Devices - Application of Risk management to Medical Devices. URL accessed on 9/4/2013 at: http://www.iso.org/iso/catalogue_detail?csnumber $=38193$.
Joskow R, Barr DB, Barr JR, Calafat AM, Needham LL, Rubin C (2006). Exposure to bisphenol A from bis-glycidyl dimethacrylate-based dental sealants. J Am Dent Assoc 137:353-362.

Kingman A, Hyman J, Masten SA, Jayaram B, Smith C, Eichmiller F, et al. (2012). Bisphenol A and other compounds in human saliva and urine associated with the placement of composite restorations. J Am Dent Assoc 143:1292-1302.

Letzel H, de Boer FA, Van't Hof MA (1997). An estimation of the size distribution of amalgam particles in dental treatment waste. $J$ Dent Res 76:780-788

Marquardt W, Seiss M, Hickel R, Reichl FX (2009). Volatile methacrylates in dental practices. $J$ Adhes Dent 11:101-107.

McManus KR, Fan PL (2003). Purchasing, installing and operating dental amalgam separators: practical issues. J Am Dent Assoc 134:1054-1065.

Moynihan P, Petersen PE (2004). Diet, nutrition and the prevention of dental diseases. Public Health Nutr 7:201-226.

Naleway CA, Ovsey V, Mihailova C, Chou H, Fan PL, Whitlock R, et al. (1994). Characteristics of amalgam in dental wastewater [abstract]. $J$ Dent Res 73:105.

Orton DI, Wilkinson JD (2004). Cosmetic allergy: incidence, diagnosis, and management. Am J Clin Dermatol 5:327-337.

Ozone Secretariat (2011). The Montreal Protocol on Substances that Deplete the Ozone Layer. URL accessed on 9/4/2013 at: http://ozone.unep.org/ new_site/en/Treaties/treaties_decisions-hb.php?sec_id $=5$.

Petersen PE (2003). The World Oral Health Report 2003: Continuous improvement of oral health in the 21 st century - the approach of the WHO Global Oral Health Programme. Community Dent Oral Epidemiol 31(Suppl 1):3-24.

Petersen PE (2005). Socio-behavioural risk factors in dental caries - international perspectives. Community Dent Oral Epidemiol 33:274-279.

Petersen PE (2008). Oral health. In: International encyclopedia of public health. Vol. 4. San Diego, CA: Academic Press, pp. 677-685.

Rotterdam Convention (2008). Rotterdam Convention on the Prior Informed Consent Procedure for Certain Hazardous Chemicals and Pesticides in International Trade. URL accessed on 9/4/2013 at: http://www.pic.int/ TheConvention/Overview/TextoftheConvention/tabid/1048/language/ en-US/Default.aspx.

SCENIHR EU (2008). The safety of dental amalgam and alternative dental restoration materials for patients and users. URL accessed on 9/4/2013 at: http://ec.europa.eu/health/ph_risk/committees/04_scenihr/docs/ scenihr_o_016.pdf.

Schmalz G, Arenholt-Bindslev D (2009). Biocompatibility of dental materials. Berlin, Heidelberg: Springer.

Schmalz G, Preiss A, Arenholt-Bindslev D (1999). Bisphenol-A content of resin monomers and related degradation products. Clin Oral Investig 3:114-119.

Schweikl H, Spagnuolo G, Schmalz G (2006). Genetic and cellular toxicology of dental resin monomers. $J$ Dent Res 85:870-877.

Stockholm Convention (2008). Convention text as amended in 2009 and 2011. URL accessed on 9/4/2013 at: http://chm.pops.int/Convention/ ConventionText/tabid/2232/Default.aspx.

Technical Committee ISO/TC 106 (1999). Dentistry, Subcommittee SC 6, Dental Equipment. Dental equipment-amalgam separators. Ref. No. ISO 11143:1999(E). Geneva, Switzerland: International Organization for Standardization.

U.S. Environmental Protection Agency (2008). Memorandum of Understanding on Reducing Dental Amalgam Discharges. URL accessed on 9/4/2013 at: http://water.epa.gov/scitech/wastetech/guide/ dental/upload/2008_12_31_guide_dental_mou.pdf.

U.S. Environmental Protection Agency (2011). Notice of Final 2010 Effluent Guidelines Program (EPA-HQ-OW-2008-0517; FRL-9483-4); American Dental Association estimates in 2003 that dental facilities contribute up to $50 \%$ of mercury entering sewage treatment plants. Federal Register 76(207):66301.

U.S. Environmental Protection Agency (2012). Dental Amalgam Effluent Guideline. URL accessed on 9/4/2013 at: http://water.epa.gov/scitech/ wastetech/guide/dental/index.cfm.

UNEP and AMAP (2013). Technical Background Report for the Global Mercury Assessment 2013. UNEP DTIE Chemicals Branch, Geneva, Switzerland. URL accessed on 9/4/2013 at: http://www.amap.no/ 
documents/doc/Technical-Background-Report-for-the-GlobalMercury-Assessment-2013/848.

UNEP (2013a). Report of the intergovernmental negotiating committee to prepare a global legally binding instrument on mercury on the work of its fifth session. [January 13-18, 2013] Avilalable from the INC5 meeting report in English at: http://www.unep.org/hazardoussubstances/ Portals/9/Mercury/Documents/dipcon/CONF_3_Minamata $\% 20$ Convention $\% 20$ on $\% 20$ Mercury_final $\% 2026 \% 2008$ _e.doc

UNEP (2013b). Global Mercury Assessment 2013: Sources, Emissions, Releases and Environmental Transport. UNEP DTIE Chemicals Branch, Geneva, Switzerland. URL accessed on 9/4/2013 at: http:// www.unep.org/hazardoussubstances/Portals/9/Mercury/GMA\%20 Report/GlobalMercuryAssessment2013.pdf.

UNEP (2013c). Mercury: Time to act. UNEP DTIE Chemicals Branch, Geneva, Switzerland. URL accessed on 9/4/2013 at: http://content. yudu.com/A20ki2/MercuryTimetoAct/resources/index.htm.

Van Landuyt KL, Yoshihara K, Geebelen B, Peumans M, Godderis L, Hoet P, Van Meerbeek B (2012). Should we be concerned about composite (nano-)dust? Dent Mater 28:1162-1170.
VanDeven JA, McGinnis SL (2005). An assessment of mercury in the form of amalgam in dental wastewater in the United States. Water Air Soil Pollution 164:349-366.

World Health Organization (2003). Diet, nutrition and the prevention of chronic diseases. WHO Technical Report Series 916. Geneva, Switzerland: WHO. URL accessed on 9/4/2013 at: http://whqlibdoc. who.int/trs/who_trs_916.pdf.

World Health Organization (2008). International health regulations (2005). 2nd ed. Geneva, Switzerland: World Health Organization. URL accessed on 9/4/2013 at: http://www.who.int/ihr/9789241596664/en/.

World Health Organization (2010). Future use of materials for dental restoration: report of the meeting convened at WHO HQ, Geneva, Switzerland, 16th to 17th November 2009. Geneva, Switzerland: World Health Organization. URL accessed on 9/4/2013 at: http://www.who. int/oral_health/publications/dental_material_2011.pdf.

World Health Organization (2011). WHO Global Oral Health Data Bank. Geneva, Switzerland: World Health Organization. URL accessed on 9/4/2013 at: http://www.who.int/whosis/whostat/EN_WHS2011_Full. pdf. 